Tropical Journal of Pharmaceutical Research April 2018; 17 (4): 569-576

ISSN: $1596-5996$ (print); 1596-9827 (electronic)

(C) Pharmacotherapy Group, Faculty of Pharmacy, University of Benin, Benin City, 300001 Nigeria.

Available online at http://www.tjpr.org

Original Research Article

http://dx.doi.org/10.4314/tjpr.v17i4.1

\title{
Design and preparation of controlled floating gastroretentive delivery systems for enhanced fexofenadine hydrochloride oral bioavailability
}

\author{
May Saab ${ }^{1^{*}}$, Wael Samy ${ }^{2}$, Mohamed Issa ${ }^{3}$, Hoda El-Maradny ${ }^{1}$ \\ ${ }^{1}$ Department of Pharmaceutical Technology, Faculty of Pharmacy, Beirut Arab University, Beirut, Lebanon, ${ }^{2}$ Department of \\ Industrial Pharmacy, Faculty of Pharmacy, Alexandria University, Alexandria, Egypt, ${ }^{3}$ Department of Pharmacy Practice, \\ Faculty of Pharmacy, Beirut Arab University, Beirut, Lebanon
}

*For correspondence: Email: saabk.may79@bau.edu.Ib, saabk.may79@yahoo.com; Tel: +961 3761032

Sent for review: 20 December 2017

Revised accepted: 19 March 2018

\begin{abstract}
Purpose: To design and prepare effervescent floating gastroretentive tablets for controlled fexofenadine hydrochloride ( $\mathrm{HCl}$ ) release and enhanced oral bioavailability.

Method: Various tablet formulations of the drug were prepared by direct compression. A systematic approach in the design of the formulations was adopted, where, first, formulations consisting of single polymers with a high polymer : sodium bicarbonate ratio were investigated for its physicochemical properties (in-vitro floating behaviour, drug release profile, etc). Next, improvement of tablets' properties was achieved by decreasing polymer : sodium bicarbonate ratio. Subsequently, a final optimization step involved blending polymers at different polymer : polymer ratios. The formulations were evaluated in vitro and in vivo in albino rabbits

Results: The formulation consisting of hydroxypropyl methylcellulose K15M/hydroxypropyl methylcellulose $K 100 \mathrm{LV}$ at $1: 2$ ratio (F8) showed good floating properties (14 s floating lag time) with nearly zero order controlled drug release for $24 h\left(R^{2}=0.9876\right)$. In-vivo bioavailability studies of F8 in albino rabbits showed a significant increase in area under the curve $(A U C, 134 \%, p<0.05)$ and hence an improvement in its oral bioavailability, compared to a commercial conventional product.

Conclusion: The good quality of the effervescent floating gastroretentive tablets of fexofenadine $\mathrm{HCl}$ developed is an indication that the approach used is suitable for the formulation of the drug for controlled drug release and enhanced oral bioavailabiliy.
\end{abstract}

Keywords: Effervescent, Floating, Gastroretentive, Fexofenadine, Bioavailability

\begin{abstract}
This is an Open Access article that uses a funding model which does not charge readers or their institutions for access and distributed under the terms of the Creative Commons Attribution License (http://creativecommons.org/licenses/by/4.0) and the Budapest Open Access Initiative (http://www.budapestopenaccessinitiative.org/read), which permit unrestricted use, distribution, and reproduction in any medium, provided the original work is properly credited.
\end{abstract}

Tropical Journal of Pharmaceutical Research is indexed by Science Citation Index (SciSearch), Scopus, International Pharmaceutical Abstract, Chemical Abstracts, Embase, Index Copernicus, EBSCO, African Index Medicus, JournalSeek, Journal Citation Reports/Science Edition, Directory of Open Access Journals (DOAJ), African Journal Online, Bioline International, Open-J-Gate and Pharmacy Abstracts

\section{INTRODUCTION}

Oral controlled drug delivery systems (OCDDS) have gained much attention for many years, as they offer several advantages over conventional drug delivery systems. These include the minimization of fluctuations in drug plasma concentrations, thereby optimizing therapeutic efficiencies and reducing side effects. In addition, these systems can reduce dosing frequency, leading to enhanced patient compliance [1]. 
Some drugs may fail to attain complete absorption and bioavailability after intake of commonly used OCDDS, as they are unable to reside at the desired area in the gastrointestinal tract (GIT). These include drugs that are degraded in the intestinal fluids or poorly soluble in the intestine, as well as those with narrow absorption window in the upper part of the gastrointestinal tract. Therefore, gastroretentive drug delivery systems (GRDDS) were developed as modified controlled release systems that are able to reside in the stomach for a prolonged period of time while controlling and targeting drug release to specific sites in the upper small intestine.

It was previously reported that GRDDS have improved the bioavailability of many drugs, such as riboflavin, L-dopa, verapamil $\mathrm{HCl}$, and captopril, by controlling their release in the upper small intestine [2].

Various methodological approaches for gastric retention have been reported in the literature, such as high density, mucoadhesive, floating, swelling and expandable systems [3]. Among these, the floating dosage forms are considered one of the important approaches to achieve gastric retention and obtain sufficient drug bioavailability [4-7].

Fexofenadine hydrochloride (Fex $\mathrm{HCl})$, a nonsedating antihistamine $\mathrm{H} 1$ blocker used for seasonal allergic rhinitis and chronic idiopathic urticaria has limited absorption in the upper small intestine with poor oral bioavailability of approximately $35 \%[8,9]$. Therefore, $\mathrm{Fex} \mathrm{HCl}$ is considered as a potential drug candidate for GRDDS. To date, there has been little research on the improvement of $\mathrm{Fex} \mathrm{HCl}$ oral bioavailability. In a previous study, a microemulsion of $\mathrm{Fex} \mathrm{HCl}$ was formulated in an attempt to improve its absorption. The bioavailability of the formulation was compared with that of a conventional marketed syrup, where the results revealed an increase in the oral bioavailability of the drug by 3.76 folds [10]. In the present study, effervescent floating GRDDS of $\mathrm{Fex} \mathrm{HCl}$ was designed for the first time as an alternative to conventional tablets, in an attempt to control drug release over $24 \mathrm{~h}$, enhance drug absorption from the proximal small intestine, and hence improve its bioavailability.

\section{EXPERIMENTAL}

\section{Materials}

Fexofenadine hydrochloride (Fex $\mathrm{HCl}$ ) and Hydroxypropylmethyl cellulose (HPMC K100LV, viscosity $8-120 \mathrm{cp}$ ) were supplied from the Jordanian Pharmaceutical Manufacturing Co. Ltd., Amman, Jordan. Hydroxypropylmethyl cellulose (HPMC K15M, viscosity $15000 \mathrm{cP}$ ) was supplied from Alexandria Pharmaceutical Co., Alexandria, Egypt. Hydroxypropylmethyl cellulose (HPMC K4M, viscosity $4000 \mathrm{cp}$ ) was purchased from Sigma-Aldrish, USA. Hydroxyethyl cellulose (HEC, Natrosol ${ }^{\circledR} 250$ MR, viscosity $6500 \mathrm{cp}$ ) was supplied from Hercules, Netherlands.

\section{Preparation of tablets}

Twelve formulations of floating tablets containing $60 \mathrm{mg} \mathrm{Fex} \mathrm{HCl}$ and different polymers were prepared by direct compression using single punch tablet machine (CP series, Vanguard Pharmaceutical Machinery, Inc. USA) equipped with $9 \mathrm{~mm}$ standard concave punch. The composition of various polymer-based tablets is illustrated in Table 1. The powders were separately passed through a sieve of $250 \mu \mathrm{m}$ aperture size, and then geometrically mixed using mortar and pestle for $5 \mathrm{~min}$. The blend of each formula (F1 - F12) was lubricated and directly compressed into tablets of average weight $250 \mathrm{mg}$. Erweka hardness tester (MT 62256, Germany) was used to measure tablets' hardness that was kept in the range of $110-120$ Newton (N).

Table 1: Composition of gastroretentive $\mathrm{Fex} \mathrm{HCl}$ tablets*

\begin{tabular}{lccccc}
$\begin{array}{l}\text { Formul } \\
\text { ation }\end{array}$ & $\begin{array}{c}\text { K4M } \\
\text { code }\end{array}$ & $\begin{array}{c}\text { KPMC } \\
\text { (mg) }\end{array}$ & $\begin{array}{c}\text { HEC } \\
(\mathbf{m g})\end{array}$ & $\begin{array}{r}\text { HPMC K100LV } \\
(\mathbf{m g})\end{array}$ & $\begin{array}{r}\text { (mg) } \\
\mathbf{C O}_{3}\end{array}$ \\
\hline F1 & 125 & - & - & - & 25 \\
F2 & - & 125 & - & - & 25 \\
F3 & - & - & 125 & - & 25 \\
F4 & - & - & - & 125 & 25 \\
F5 & - & 100 & - & - & 50 \\
F6 & - & - & 100 & - & 50 \\
F7 & - & 50.0 & - & 50.0 & 50 \\
F8 & - & 33.3 & & 66.7 & 50 \\
& & & & & \\
F9 & - & 25.0 & - & 75.0 & 50 \\
F10 & - & - & 50.0 & 50.0 & 50 \\
F11 & & - & 33.3 & 66.7 & 50 \\
F12 & & - & 25.0 & 75.0 & 50 \\
\hline
\end{tabular}

*Each tablet contained $60 \mathrm{mg}$ Fex $\mathrm{HCl}, 22.5 \mathrm{mg}$ lactose, $12.5 \mathrm{mg}$ polyvinyl pyrrolidone and $5 \mathrm{mg}$ magnesium stearate : talc $(1: 9)$ as a lubricant 


\section{In-vitro floating properties}

In-vitro floating of all compressed tablets was determined in triplicate using a $100 \mathrm{~mL}$ Nessler tube containing $0.1 \mathrm{~N} \mathrm{HCl}(\mathrm{pH} 1.2)$. The time taken by the tablets to float on the surface of the medium was defined as the floating lag time (s.) and the total time taken by the tablets to maintain floating was defined as the floating duration (h) [11].

\section{In-vitro drug release study}

The release of $\mathrm{Fex} \mathrm{HCl}$ from tablet formulations (F1 - F12) was studied using USP dissolution apparatus II. The dissolution test was performed in $900 \mathrm{ml}$ of $0.1 \mathrm{~N}$ hydrochloric acid $(\mathrm{pH} 1.2)$ maintained at $37 \pm 0.5^{\circ} \mathrm{C}$ and rotated at $50 \mathrm{rpm}$. Five $\mathrm{ml}$ were withdrawn at different time intervals, filtered through a $0.45 \mu \mathrm{m}$ millipore filter and suitably diluted. Samples were analyzed spectrophotometrically at $220 \mathrm{~nm}$. The average percentage drug release of three determinations was plotted against time to determine the release profiles.

\section{In-vitro drug release kinetics}

The release data were fitted to Zero-order, Firstorder, Higuchi's equation and Hixson-Crowell equation. Furthermore, the drug release mechanisms for the studied polymeric systems were analyzed using Korsmeyer-Peppas model [12]:

Qt / $Q_{\infty}=k_{k p} \cdot t^{n}$

Where $Q_{t} / Q_{\infty}$ is the fraction of drug released at time; $t, k_{k p}$ is a constant comprising the structural and geometric characteristics of the tablet, and $n$ is the release exponent, which indicates the drug release mechanism.

\section{In-vivo evaluation of the selected formulation}

\section{In-vivo floating properties}

In-vivo floating properties of the selected formula was evaluated using $\mathrm{x}$-ray imaging technique (MD-8000, Mediconex, China) by incorporating barium sulphate $\left(\mathrm{BaSO}_{4}\right)$ as a radiopaque contrast agent in the formulation. The total replacement of $\mathrm{Fex} \mathrm{HCl}$ by the highly dense $\mathrm{BaSO}_{4}$ impeded the floating properties of tablets when examined in-vitro. In an attempt to clearly observe the floating behaviour of the tablet in the rabbit's stomach without affecting its floating properties, half amount of the drug $(30 \mathrm{mg})$ in the tablet's formulation was replaced by $\mathrm{BaSO}_{4}$.
The in-vivo floating study was carried out by administering the tablet to an overnight fasted albino rabbit $(2.25 \mathrm{~kg})$ with $30 \mathrm{~mL}$ of water. The rabbit was anesthetized and then fixed by his limbs in the upright position on a board, in order to be monitored by $x$-ray screening technique to locate the tablet. Different $x$-ray photographs were taken after $0.5,3$ and $6 \mathrm{~h}$.

\section{In-vivo bioavailability}

Eight healthy male albino rabbits weighing between 2.2 and $2.5 \mathrm{~kg}$ were used for the in-vivo pharmacokinetic study of the selected formula and the $60 \mathrm{mg}$ conventional marketed product (MP).

Ethical approval was obtained from the institutional review board (IRB) committee, Beirut Arab University, Lebanon, for conducting this study (protocol approval no. $2014 \mathrm{~A} / 018 / \mathrm{P} / \mathrm{P} / 0030$ ), that was carried out following the US national guideline for animal studies [13].

Rabbits were divided into two groups and fasted overnight. MP was administered to Group A, while group B was given the selected gastroretentive tablet formulation.

Blood samples $(1 \mathrm{~mL})$ were withdrawn from the marginal ear vein and collected in heparinized tubes. Plasma samples were separated by centrifugation at $10,000 \mathrm{rpm}$ for 10 minutes using centurion centrifuge (Centurion Scientific LTD, UK) and stored at $-20^{\circ} \mathrm{C}$ until further analysis [10].

Samples were freeze-thawed and extracted by adding $0.5 \mathrm{~mL}$ acetonitrile. The resultant supernatant was evaporated to dryness under nitrogen gas for about $10 \mathrm{~min}$, and the obtained residue was reconstituted with $1 \mathrm{~mL}$ of the mobile phase $(\mathrm{pH} 3.5)$ consisting of acetonitrile and $0.5 \%$ potassium dihydrogen phosphate buffer $(35: 65 \% \mathrm{v} / \mathrm{v})$. An aliquot of $20 \mu \mathrm{L}$ of each sample was then analyzed by Reverse PhaseHPLC method [14]. Pharmacokinetic analysis was performed by means of pk solver 2.0 program.

The relative bioavailability (B) of the selected tablet was calculated as in Eq 2.

$B=(A \cup C s / A \cup C m p) 100$

where, AUCs and AUCmp are the areas under the curve for the selected tablet and the marketed product, respectively. 


\section{Statistical analysis}

Statistical analysis for in-vivo bioavailability study was conducted using the statistics software SPSS 20 (SPSS Inc., Chicago, USA). The significance of the difference between the mean AUCs and the mean AUCmp was analyzed by applying t-test, where a $p$ value of less than 0.05 was considered statistically significant.

\section{RESULTS}

\section{Floating properties}

The effect of polymer type, polymer : sodium bicarbonate ratio, and polymer blends on the floating properties of tablets are summarized in Table 2.

Formulations based on single polymers and comprising $125 \mathrm{mg}$ polymer and $25 \mathrm{mg}$ sodium bicarbonate per tablet (F1 - F4) showed a significant variation in their floating properties. Tablets formulated with the highest viscosity polymer, namely, HPMC K15M (F2) revealed the longest floating lag time (630 $\pm 96 \mathrm{~s})$, followed by HEC (F3) and HPMC K4M (F1), recording $450 \pm$ $162 \mathrm{~s}$ and $12.3 \pm 1.5 \mathrm{~s}$, respectively. The floating duration of $\mathrm{F} 1, \mathrm{~F} 2$ and $\mathrm{F} 3$ tablets exceeded $24 \mathrm{~h}$. However, F4 tablets containing HPMC K100LV sank immediately and underwent fast disintegration in less than $2 \mathrm{~h}$.

In an attempt to decrease the floating lag time of HPMC K15M and HEC-based tablets, formulations with a lower polymer content (100 $\mathrm{mg} / \mathrm{tablet}$ ) and a higher amount of sodium bicarbonate (50 mg/tablet) were investigated (F5 and F6). Generally, it was noticed that formulations with a higher amount of sodium bicarbonate decreased the floating lag time. For instance, the floating lag time of F5 tablets decreased by approximately $156 \mathrm{~s}$ when compared to F2.
Blends of high viscosity (HPMC K15M or HEC) and low viscosity polymers (HPMC K100LV) revealed further improvement in the floating properties of tablets (F7 - F11). Generally, the increase in the amount of HPMC K100LV decreased the floating lag time of all tablet formulations, except for F12 that failed to float and disintegrated gradually.

\section{In-vitro drug release profile}

The release profiles of all tablet formulations are illustrated in Table 2. The highest drug release was observed with HPMC K4M-based formulation (F1), and the lowest was recorded for HPMC K15M-based formulation (F2), where the drug release at $1 \mathrm{~h}$ for $\mathrm{F} 1$ was about 8.5 -fold that of F2. Despite a sustained drug release for over $24 \mathrm{~h}, \mathrm{~F} 1$ formulation revealed a high burst effect (Table 2). On the other hand, HPMC K15M and HEC-based tablets (F2 and F3) recorded a low initial drug release at $1 \mathrm{~h}$. However, an incomplete drug release was observed (36.6 \pm 0.4 and $54.3 \pm 0.8 \%$, at $24 \mathrm{~h}$ for F2 and F3, respectively). A decrease in the amount of HPMC K15M and HEC polymer (F5 and F6, respectively) did not show a remarkable improvement in the release behaviour of tablets. On the other hand, drug release rates of formulations consisting of polymer blends of HPMC K15M : HPMC K100LV (Figure 1) and HEC : HPMC K100LV (Figure 2) were significantly higher than those with single polymers ( $\mathrm{F} 5$ and $\mathrm{F} 6$ ). A gradual increase in the amount of the low viscosity polymer (HPMC $\mathrm{K} 100 \mathrm{LV}$ ) resulted in a gradual increase in drug release rate. As a result, F8, F9 and F10 were considered as promising formulations for further investigation, as they displayed favourable drug release profiles among all formulations, by providing a low initial burst and a sustained drug release for $24 \mathrm{~h}$.

Table 2: In-vitro floating and drug release data of $\mathrm{Fex} \mathrm{HCl}$ tablets

\begin{tabular}{|c|c|c|c|c|c|c|}
\hline $\begin{array}{l}\text { Formulation } \\
\text { code }\end{array}$ & $\begin{array}{c}\text { Floating } \\
\text { lag time (s) }\end{array}$ & $\begin{array}{l}\text { Drug release } \\
\qquad(\%, 1 \mathrm{~h})\end{array}$ & $\begin{array}{l}\text { Drug } \\
\text { release } \\
(\%, 8 \mathrm{~h})\end{array}$ & $\begin{array}{c}\text { Drug release } \\
(\%, 24 \mathrm{~h})\end{array}$ & $\begin{array}{l}T_{50} \\
\text { (h) }\end{array}$ & $\begin{array}{l}T_{90} \\
\text { (h) }\end{array}$ \\
\hline $\mathrm{F} 1$ & $12.3 \pm 1.5$ & $30.8 \pm 0.8$ & $62.7 \pm 1.1$ & $85.1 \pm 0.3$ & $3.7 \pm 0.2$ & $23.8 \pm 0.3$ \\
\hline $\mathrm{F} 2$ & $630 \pm 96$ & $3.6 \pm 0.2$ & $18.5 \pm 0.6$ & $36.6 \pm 0.4$ & $>24$ & $>24$ \\
\hline F3 & $450 \pm 162$ & $4.1 \pm 0.1$ & $24.2 \pm 1.0$ & $54.3 \pm 0.8$ & $>24$ & $>24$ \\
\hline F5 & $474 \pm 84$ & $3.7 \pm 0.1$ & $23.1 \pm 1.0$ & $46.7 \pm 0.7$ & $>24$ & $>24$ \\
\hline F6 & $390 \pm 30$ & $7.1 \pm 0.2$ & $33.1 \pm 1.2$ & $54.8 \pm 1.5$ & $20.3 \pm 0.7$ & $>24$ \\
\hline F7 & $168 \pm 12$ & $11.6 \pm 0.6$ & $43.4 \pm 1.2$ & $82.6 \pm 1.7$ & $10.9 \pm 0.2$ & $>24$ \\
\hline F8 & $33.3 \pm 3.6$ & $14.0 \pm 0.6$ & $52.6 \pm 1.3$ & $94.8 \pm 2.4$ & $7.6 \pm 0.3$ & $21.9 \pm 0.7$ \\
\hline F9 & $15.5 \pm 0.5$ & $17.7 \pm 0.7$ & $69.7 \pm 1.3$ & $101.1 \pm 1.3$ & $5.3 \pm 0.1$ & $13.8 \pm 0.9$ \\
\hline F10 & $47.3 \pm 2.5$ & $15.1 \pm 0.7$ & $60.6 \pm 1.2$ & $98.4 \pm 0.3$ & $6.2 \pm 0.1$ & $19.1 \pm 0.7$ \\
\hline F11 & $14.0 \pm 2.0$ & $31.5 \pm 0.9$ & $86.1 \pm 1.3$ & $101.3 \pm 0.9$ & $1.9 \pm 0.1$ & $9.4 \pm 0.6$ \\
\hline
\end{tabular}




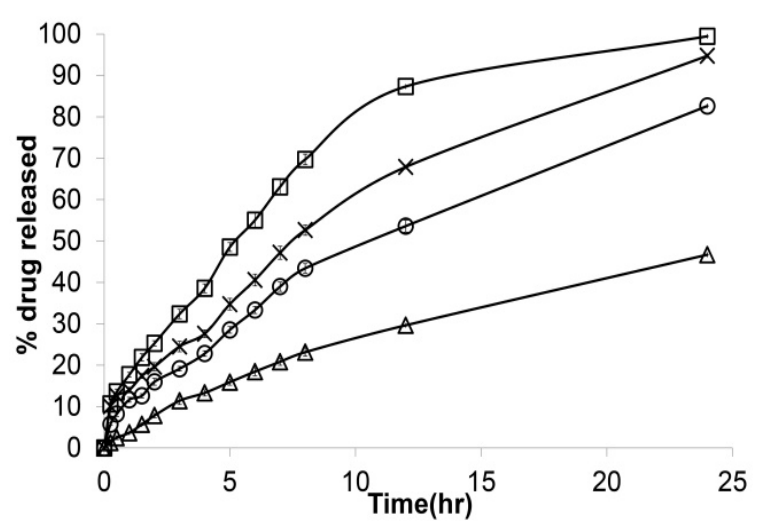

Figure 1: Release profiles of $\mathrm{Fex} \mathrm{HCl}$ tablets based on polymer blends [HPMC K15M polymer alone (F5, $\Delta$ ), and HPMC K15M : HPMC K100LV polymer blends at $1: 1(\mathrm{~F} 7, \mathrm{O}), 1: 2(\mathrm{~F} 8, \times)$ and $1: 3(\mathrm{F9}, \square)$ ratios]

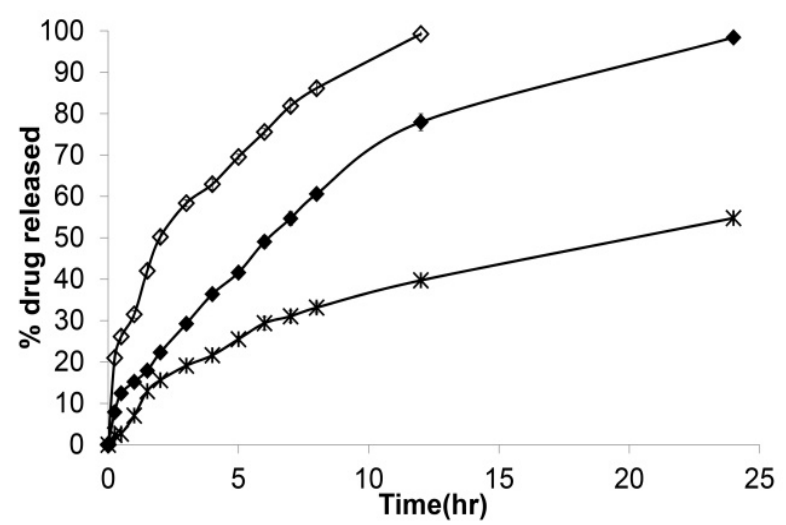

Figure 2: Release profile of $\mathrm{Fex} \mathrm{HCl}$ tablets based on polymer blends [HEC polymer alone (F6,*), and HEC : HPMC K100LV polymer blends at $1: 1(\mathrm{~F} 10, \diamond)$ and $1: 2(\mathrm{~F} 11, \diamond)$ ratios]

\section{Drug release kinetics}

The drug release kinetics data are illustrated in Table 3. Most of the formulations showed anomalous transport mechanism (diffusion and erosion), where their $n$ values ranged between 0.45 and 0.85 . Among the three selected formulations (F8, F9 and F10), F8 was chosen for in-vivo investigation, as its release profile revealed the highest correlation with zero order kinetics $\left(R^{2}=0.9876\right)$, indicating a nearly constant drug release rate.

\section{In-vivo floating behaviour of the selected formulation (F8)}

In order to observe the in-vivo floating behaviour of the selected tablet (F8) by $x$-ray imaging, Fex $\mathrm{HCl}$ was totally replaced by $\mathrm{BaSO}_{4}$ in the tablet formulation. In-vitro investigation of $\mathrm{BaSO}_{4}-$ tagged tablet showed no floating at all due the high density of $\mathrm{BaSO}_{4}$. On the other hand, the replacement of half amount of the drug by $\mathrm{BaSO}_{4}$ resulted in an acceptable in-vitro floating behaviour, by recording a floating lag time of 216 $\pm 18 \mathrm{~s}$ and a floating duration of $8 \mathrm{~h}$. Accordingly, in-vivo floating behaviour of the latter was investigated in albino rabbit, using $x$-ray imaging technique. Figure 3 shows the $x$-ray photographs of an empty abdomen (zero time) and after $0.5,3$ and $6 \mathrm{~h}$ of tablet administration. The tablet floated in the stomach region while swelling, and remained buoyant in the stomach with a relative decrease in tablet dimension as a result of erosion.
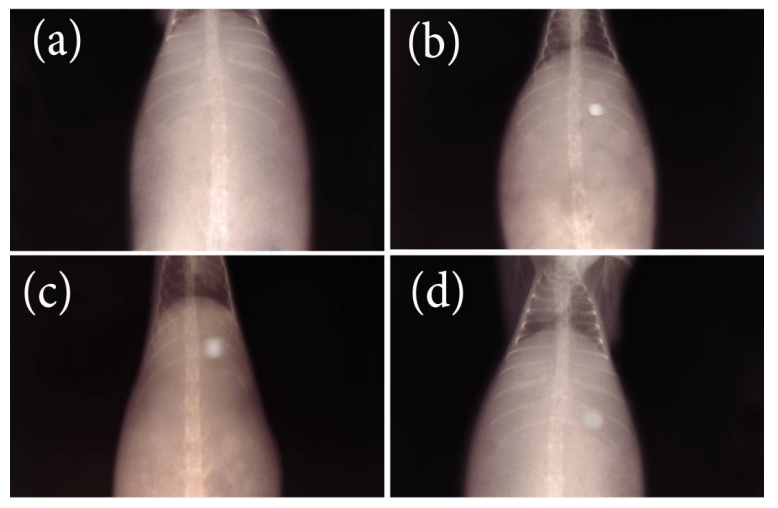

Figure 3: X-ray photographs of albino rabbit's abdomen region; (a) before tablet administration, (b) $0.5 \mathrm{~h}, \quad$ (c) $3 \mathrm{~h}$ and (d) $6 \mathrm{~h}$, following tablet administration.

Table 3: Drug release kinetics data

\begin{tabular}{lcccccc}
\hline $\begin{array}{l}\text { Formulation } \\
\text { code }\end{array}$ & $\begin{array}{c}\text { Zero order } \\
\mathbf{R}^{\mathbf{2}}\end{array}$ & $\begin{array}{c}\text { First order } \\
\mathbf{R}^{\mathbf{2}}\end{array}$ & $\begin{array}{c}\text { Higuchi } \\
\mathbf{R}^{\mathbf{2}}\end{array}$ & $\begin{array}{c}\text { Hixson-Crowell } \\
\mathbf{R}^{\mathbf{2}}\end{array}$ & $\begin{array}{c}\text { Korsmeyer-Peppas } \\
\mathbf{R}^{\mathbf{2}}\end{array}$ & $\mathbf{n}$ \\
\hline F1 & 0.8326 & 0.9197 & 0.9739 & 0.8941 & 0.9804 & 0.42 \\
F2 & 0.9803 & 0.9779 & 0.9703 & 0.9789 & 0.8851 & 0.84 \\
F3 & 0.9671 & 0.9466 & 0.9698 & 0.9336 & 0.9594 & 0.73 \\
F5 & 0.9941 & 0.9863 & 0.9754 & 0.9634 & 0.9508 & 0.81 \\
F6 & 0.9792 & 0.9258 & 0.9846 & 0.8995 & 0.9511 & 0.65 \\
F7 & 0.9509 & 0.9958 & 0.9728 & 0.9963 & 0.9824 & 0.69 \\
F8 & 0.9876 & 0.9377 & 0.9752 & 0.9961 & 0.9540 & 0.61 \\
F9 & 0.9849 & 0.9831 & 0.9694 & 0.9898 & 0.9735 & 0.56 \\
F10 & 0.9212 & 0.9613 & 0.9701 & 0.9958 & 0.9608 & 0.63 \\
F11 & 0.9454 & 0.9705 & 0.9650 & 0.9801 & 0.9491 & 0.59 \\
\hline
\end{tabular}


Pharmacokinetics of the selected formulation (F8)

The plasma concentration-time profiles of Fex $\mathrm{HCl}$ and its pharmacokinetic parameters, after the administration of MP and the selected GR tablet (F8) to healthy albino rabbits are illustrated in Figure 4. The time needed to attain $\mathrm{C}_{\max }$ was doubled for F8 (4 $\pm 0 \mathrm{~h})$ compared to MP ( $2 \pm 0$ h). Moreover, Fex $\mathrm{HCl}$ plasma level from F8 was still detectable at $24 \mathrm{~h}$ post-administration, whereas that from MP disappeared after $12 \mathrm{~h}$.

The AUC of F8 (53.68 $\pm 5.52 \mu \mathrm{g} / \mathrm{mL} . \mathrm{h})$ was significantly higher than that of MP (39.93 \pm 7.11 $\mu \mathrm{g} / \mathrm{mL} . \mathrm{h})(p<0.05)$, indicating an enhancement in the oral bioavailability of the drug.

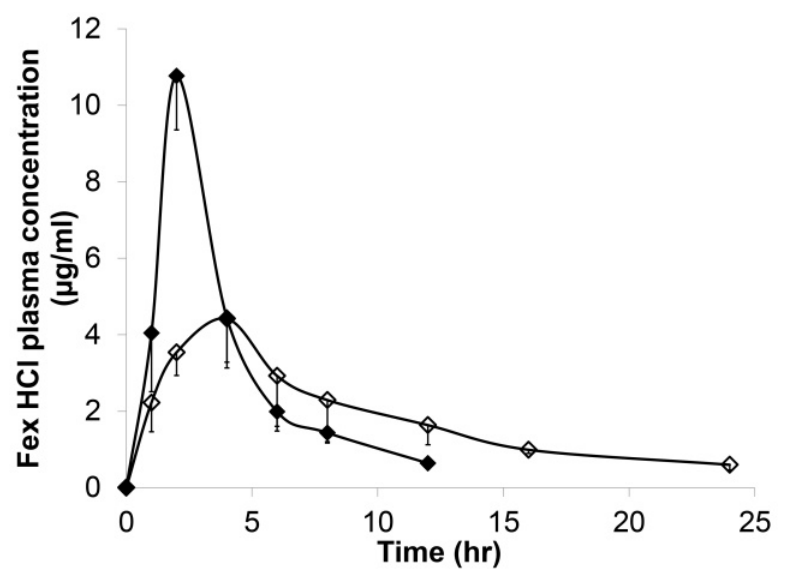

Figure 4: Plasma concentration-time profiles of Fex $\mathrm{HCl}$ after administration of the MP $(\bullet)$ and selected GR tablet F8 $(\diamond)($ mean \pm SD, $n=4)$

\section{DISCUSSION}

Gastroretentive effervescent floating tablets of Fex HCL were designed in an attempt to control drug release and improve its oral bioavailability. The selection of the polymer type and the appropriate polymer : sodium bicarbonate ratio is vital to attain a controlled drug release profile while retaining good floating properties. Therefore, different tablet formulations consisting of single polymers of various viscosities and at a constant polymer : sodium bicarbonate ratio ( 5 : 1) were investigated as a preliminary step. The floating behaviour of gastroretentive effervescent floating tablets is mainly attributed to the gas generation resulting from the interaction of sodium bicarbonate with the acidic medium, and its entrapment within the polymeric matrix [15].

In the present study, the highly viscous polymers in $\mathrm{F} 2$ and $\mathrm{F} 3$ formulation may have played a major role in retarding the floating of tablets as a result of delaying the ingress of acidic medium into the polymeric matrix (Table 2). This resulted in slowing down the interaction between sodium bicarbonate and acidic medium $(0.1 \mathrm{~N} \mathrm{HCl})$ and hence slowing the gas formation process that initiates the floating. In an earlier study, the effect of different polymer viscosities on the floating behaviour of cinnarazine effervescent GR tablets was investigated, where an increase in the floating lag time was demonstrated with increasing the viscosity of the polymer [16].

However, formulation with low viscosity polymer (F4) failed to float, as it prohibited the entrapment of gas that was instantly dissipated from the tablet matrix [17].

A decrease in polymer : sodium bicarbonate ratio $(2: 1)$ contributed to the decrease in the floating lag time of HPMC K15M and HEC based formulations (F5 and F6, respectively). This is in agreement with previous studies, where higher amounts of the effervescent agent resulted in an increase in gas generation and hence faster floating $[18,19]$.

Moreover, blending high viscosity (HPMC K15M or HEC) and low viscosity (HPMC K100LV) polymers (F7 - F11) resulted in a further decrease in the floating lag time. Low viscosity polymer facilitated diffusion of the acidic medium into the tablet matrix and hence its interaction with sodium bicarbonate to generate $\mathrm{CO}_{2}$ [20].

On the other hand, failure of formulation $\mathrm{F} 12$ to float could be explained by the inability of the polymeric matrix to efficiently hold the generated $\mathrm{CO}_{2}$ gas as a result of the low viscous medium imparted by the high amount of HPMC K100LV. Furthermore, the loss of matrix integrity may have worsened its floating properties [21].

Upon investigating the drug release profile from different formulations (Table 2), the slowest drug release was observed in F2 and F3 formulations. A very viscous polymeric network was particularly formed which may have affected the drug diffusion through this network and eventually may be responsible for an incomplete drug release [21].

A decrease in polymer : sodium bicarbonate ratio (F5 and F6) did not remarkably enhance the drug release profile, where the attainment of a controlled and complete drug release at $24 \mathrm{~h}$ is sought (Table 2). Therefore, different blends of high and low viscosity polymers were employed, that showed an improvement in drug release behaviour (Figure 2 and Figure 3) while retaining good floating properties. These findings are in accordance with those obtained by Mostafavi et 
al [23] who revealed an increase in ciprofloxacin release rate upon mixing a low viscosity polymer ( $\mathrm{Na} \mathrm{CMC}$ ) with the highly viscous one (HPMC K100M).

From all previous findings, F8 tablet formulation containing $100 \mathrm{mg}$ of high and low viscosity polymer (HPMC K15M : HPMC K100M at a ratio of $1: 2$, respectively), and $50 \mathrm{mg}$ sodium bicarbonate was chosen as the best formulation for further investigation. It showed excellent floating properties (<1 min floating lag time), a sustained release profile for $24 \mathrm{~h}(14,52.6$ and $94.8 \%$ drug release at 1,8 and $24 \mathrm{~h}$, respectively), and zero order release kinetics $\left(R^{2}\right.$ $=0.9876$ ), thus providing a controlled and nearly a constant drug release rate.

The selected tablet revealed good in-vivo floating properties, by recording a floating duration for over $6 \mathrm{~h}$. Similarly, in a study conducted by Trivedi et al [24], the in-vivo floating behaviour of ranitidine $\mathrm{HCl}$ gastroretentive tablets was investigated in a human volunteer. They observed a floating duration of approximately $7 \mathrm{~h}$ in the stomach.

The AUC of $\mathrm{F} 8$ was $135 \%$ higher than that of MP $(p<0.05)$. This could be attributed to its prolonged gastric residence time and hence its controlled drug release in the upper region of the small intestine, which may have improved drug absorption and increased its oral bioavailability [7].

\section{CONCLUSION}

The findings of this study demonstrate that gastroretentive effervescent floating tablets of Fex $\mathrm{HCl}$ is a promising approach to control the release of the drug and enhance its oral bioavailabiliy. Moreover, the simplicity of the design of the formulation and ease of production should facilitate its adaptation to large-scale manufacture.

\section{DECLARATIONS}

\section{Acknowledgement}

The authors would like to thank Prof. Dr. Azza Ghazi (Professor of Pharmaceutical Analytical Chemistry and Drug Quality Control, Pharmaceutical Technology Department, Beirut Arab University) and Mrs Souhayla Hindawi (Technical Assistant in the Drug Quality Control Lab, Beirut Arab University) for their help and guidance during HPLC analysis.

\section{Conflict of interest}

No conflict of interest is associated with this work.

\section{Contribution of authors}

The authors declare that this work was done by the authors named in this article and all liabilities pertaining to claims relating to the content of this article will be borne by them.

\section{REFERENCES}

1. Streubel A, Siepmann J, Bodmeier R. Drug delivery to the upper small intestine window using gastroretentive technologies. Curr Opin Pharmacol 2006; 6(5): 501-508.

2. Abdul S, Mallikarjun B, Mohiuddin M, Sheshgiri G, Noorulla S. Gastro Retentive Drug Delivery Systems: A Review. Pharm Lett 2011; 3(1): 121-137.

3. Prajapati VD, Jani GK, Khutliwala TA, Zala BS. Raft forming system-an upcoming approach of gastroretentive drug delivery system. $J$ Control Release 2013; 168(2): 151-165.

4. Yusif RM, Abu H, II, Mohamed EA, El Rakhawy MM. Investigation and Evaluation of an in Situ Interpolymer Complex of Carbopol with Polyvinylpyrrolidone as a Matrix for Gastroretentive Tablets of Ranitidine Hydrochloride. Chem Pharm Bull (Tokyo) 2016; 64(1): 42-51.

5. Vo $A Q$, Feng $X$, Morott JT, Pimparade MB, Tiwari RV, Zhang $F$, Repka MA. A novel floating controlled release drug delivery system prepared by hot-melt extrusion. Eur J Pharm Biopharm 2016; 98: 108-21.

6. Chug $C$, Nanda A. Gastrortentive drug delivery systemsA review. Int J Pharm Biol Sci 2017; 8(1): 62-68.

7. Thakar K, Joshi G, Sawant KK. Bioavailability enhancement of baclofen by gastroretentive floating formulation: statistical optimization, in vitro and in vivo pharmacokinetic studies. Drug Dev Ind Pharm 2013; 39(6): 880-888.

8. Tahara $H$, Kusuhara $H$, Fuse $E$, Sugiyama $Y$. $P$ glycoprotein plays a major role in the efflux of fexofenadine in the small intestine and blood-brain barrier, but only a limited role in its biliary excretion. Drug Metab Dispos 2005; 33(7): 963-968.

9. Lappin G, Shishikura $Y$, Jochemsen R, Weaver RJ, Gesson C, Houston B, Oosterhuis B, Bjerrum OJ, Rowland M, Garner C. Pharmacokinetics of fexofenadine: Evaluation of a microdose and assessment of absolute oral bioavailability. Eur J Pharm Sci 2010; 40(2): 125-131.

10. Gundogdu E, Alvarez IG, Karasulu E. Improvement of effect of water-in-oil microemulsion as an oral delivery system for fexofenadine: in vitro and in vivo studies. Int J Nanomedicine 2011; 6: 1631-1640.

11. Oh TO, Kim JY, Ha JM, Chi SC, Rhee YS, Park CW, Park ES. Preparation of highly porous gastroretentive 
metformin tablets using a sublimation method. Eur $J$ Pharm Biopharm 2013; 83(3): 460-467.

12. Korsmeyer RW, Gurny R, Doelker E, Buri P, Peppas NA. Mechanisms of solute release from porous hydrophilic polymers. Int J Pharm 1983; 15(1): 25-35.

13. Barthold SW, Bayne KA, Davis MA. Guide for the care and use of laboratory animals. Washington: National Academy Press 2011.

14. Miura M, Uno T, Tateishi T, Suzuki T. Determination of fexofenadine enantiomers in human plasma with highperformance liquid chromatography. J Pharm Biomed Anal 2007; 43(2): 741-745.

15. Razavi $M$, Karimian $H$, Yeong $C H$, Sarji $S A$, Chung $L Y$, Nyamathulla S, Noordin MI. Gamma scintigraphic study of the hydrodynamically balanced matrix tablets of Metformin HCl in rabbits. Drug Des Devel Ther 2015; 9: 3125-3139.

16. Nagarwal RC, Ridhurkar DN, Pandit JK. In vitro release kinetics and bioavailability of gastroretentive cinnarizine hydrochloride tablet. AAPS PharmSciTech 2010; 11(1): 294-303.

17. Jagdale SC, Agavekar AJ, Pandya SV, Kuchekar BS, Chabukswar AR. Formulation and evaluation of gastroretentive drug delivery system of propranolol hydrochloride. AAPS PharmSciTech 2009; 10(3): 10711079.

18. Kumar R, Patil S, Patil M, Patil SR, Paschapur MS. Design and In vitro evaluation of oral floating matrix tablets of Aceclofenac. Int J Chem Tech Res 2009; 1(4): 815-825.

19. Kumar S, Sahu RK, Sharma S, Sharma S, Jangde R. Design and evaluation of an oral floating matrix tablet of salbutamol sulphate. Trop J Pharm Res 2012; 11(4): 569-576.

20. Chen Y-C, Ho H-O, Lee T-Y, Sheu M-T. Physical characterizations and sustained release profiling of gastroretentive drug delivery systems with improved floating and swelling capabilities. Int J Pharm 2013; 441(1): 162-169.

21. Shakya $R$, Thapa $P$, Saha $R N$. In vitro and in vivo evaluation of gastroretentive floating drug delivery system of ofloxacin. Asian J Pharm Sci 2013; 8(3): 191 198.

22. Badhan AC, Mashru RC, Shah PP, Thakkar AR, Dobaria $N B$. Development and evaluation of sustained release gastroretentive minimatrices for effective treatment of $\mathrm{H}$. pylori infection. AAPS PharmSciTech 2009; 10(2): 459467.

23. Mostafavi A, Emami J, Varshosaz J, Davies NM, Rezazadeh M. Development of a prolonged-release gastroretentive tablet formulation of ciprofloxacin hydrochloride: Pharmacokinetic characterization in healthy human volunteers. Int J Pharm 2011; 409(1): 128-136.

24. Trivedi N, Trivedi U, Patel M, Patel J, Bhandari A. Preparation and evaluation of floating matrix tablet of ranitidine. Amer J Drug Disco Dev 2011; 1: 8-23. 